\title{
DESAFIOS DA ENERGIA FOTOVOLTAICA E AÇÕES DE SUSTENTABILIDADE PARA O PROGRAMA HABITACIONAL “MINHA CASA, MINHA VIDA"
}

\author{
Thais de Morais Souza ${ }^{1}$, Maria Emilia Martins Ferreira ${ }^{2}$ \\ 1, 2 Universidade Federal do Paraná, Curitiba, Paraná, Brasil - thais.morais.sustentabilidade@gmail.com \\ \&mariaemilia@ufpr.br
}

\begin{abstract}
RESUMO
O Brasil passa por uma crise no seu sistema de abastecimento energético, o que faz com que todos os setores da sociedade tenham de buscar por fontes alternativas de energia, principalmente limpas e renováveis, para suprirem as demandas atuais e futuras. Na busca de uma nova solução para o problema e com o objetivo de verificar a viabilidade do uso da energia solar fotovoltaica para o abastecimento das residências do Programa "Minha Casa, Minha Vida", em suas faixas 2 e 3, foi realizado um estudo sobre os pontos positivos e negativos da implantação dessa modalidade de geração de energia dentro das faixas do programa. Foi realizada uma pesquisa qualitativa, explicativa, com mais de 1.500 entrevistados cujo objetivo era verificar se a população possui conhecimento e incentiva as ações de sustentabilidade, energia fotovoltaica e incentivos indiretos destas ações das construtoras em seus empreendimentos imobiliários. Com base nos dados coletados, foi possível verificar que há viabilidade em se implantar nos empreendimentos a geração de energia fotovoltaica, haja visto que as construtoras pioneiras no processo terão um retorno positivo, além de seus clientes, o meio ambiente e a matriz energética brasileira. Atualmente, no país, apenas uma construtora realiza a implantação de sistema fotovoltaico e ações de sustentabilidade no programa de habitação popular "Minha Casa, Minha Vida", desta forma, será estudado apenas esta construtora.
\end{abstract}

PALAVRAS-CHAVE: Construção Sustentável, Energia Fotovoltaica, Energia Solar, Habitação Popular, Matriz Energética, Programa "Minha Casa, Minha Vida".

\begin{abstract}
Brazil is experiencing a crisis in its energy supply system, which means that all sectors of society must find alternative sources of energy, mainly clean and renewable, to meet current and future demands. In the search for a new solution to the problem and with the objective of verifying the viability of the use of photovoltaic solar energy to supply the residences of the "Minha Casa, Minha Vida" Program, in its tracks 2 and 3, a study was carried out on the positive and negative points of implementing this modality of energy generation within the program. A qualitative and explanatory research was carried out with more than 1,500 respondents whose objective was to verify if the population has knowledge and encourages the actions of sustainability, photovoltaic energy and indirect incentives of these actions of the builders in their real estate projects. Based on the data collected, it was possible to verify that it is feasible to implement photovoltaic energy generation in the projects, since the pioneers in the process will have a positive return, in addition to their clients, as well as the environment and the energy matrix Brazilian At the present moment in the country, only one construction company realizes the implantation of photovoltaic system and sustainability actions in the popular housing program "Minha Casa, Minha Vida", in this way, we will only work with this construction company.
\end{abstract}

KEYWORDS: Sustainable Building, Photovoltaic Energy, Solar Energy, Energy Matrix, Popular Housing, "Minha Casa, Minha Vida" Program. 


\section{INTRODUÇÃO}

O direito à moradia é um direito fundamental do cidadão garantido pela Constituição de 1988 e assegurado no art. 11 do Pacto Internacional dos Direitos Econômicos, Sociais e Culturais, no art. 60 da Constituição Brasileira e assegurado pelo art. 25 da Declaração Universal dos Direitos Humanos que implicam, em seu conjunto, na observância dos direitos à saúde, ao bem estar, aos serviços sociais, à vida e ao meio ambiente ecologicamente equilibrado e saudável, "suprindo as necessidades presente sem interferir nas gerações futuras".

Ciente do déficit de habitação no Brasil, o Governo Federal implantou o Programa Minha Casa Minha Vida, que oferece condições atrativas para o financiamento de moradias nas áreas urbanas para famílias de baixa renda. Em parceria com estados, municípios, empresas e entidades sem fins lucrativos, o programa vem mudando a vida de milhares de famílias brasileiras.

Atualmente no Programa Minha Casa, Minha Vida, existem quatro faixas de renda contempladas. São elas:

- Faixa 1: Famílias com renda de até $\mathrm{R} \$ 1.800,00$;

- Faixa 1,5: Famílias com renda de até $\mathrm{R} \$ 2.600,00$;

- Faixa 2: Famílias com renda de até $\mathrm{R} \$ 4.000,00$;

- Faixa 3: Famílias com renda de até $\mathrm{R} \$ 7.000,00$.

Segundo o Ministério do Meio Ambiente (MMA, 2018) sobre construção sustentável, os desafios para o setor da construção são diversos, porém, em síntese, consistem na redução e na otimização do consumo de materiais e energia, na redução dos resíduos gerados, na preservação do ambiente natural e na melhoria da qualidade do ambiente construído.

Nos últimos anos, a falta de chuva por longos períodos bem como a falta de investimento no setor energético no Brasil tem impactado diretamente na economia das empresas que dependem $100 \%$ da energia elétrica para seu funcionamento. Devido a essa recessão hídrica, se faz necessário acionar usinas termelétricas com energia mais poluente e cara, acarretando em aumentos de até $60 \%$ na conta de energia, segundo ABSOLAR (2016).

$A$ geração de energia alternativa tornou-se uma saída viável para as empresas em que a energia fotovoltaica é uma solução para tirar muitas empresas do vermelho. Essa alternativa tem sido adotada por empresas de todos os portes em que a geração distribuída, os benefícios de incentivos governamentais de crédito para a adoção de tecnologias sustentáveis de geração de energia tem sido o grande propulsor. Isso sem considerar os impactos positivos na imagem da empresa pela adoção de energias renováveis, que contribui, também, para a sustentabilidade e preservação do meio ambiente.

O potencial de geração de energia fotovoltaica no Brasil é muito grande, principalmente se se levar em consideração que países com incidências menores de energia solar tem projetos de aproveitamento de energia fotovoltaica mais desenvolvidos, tais como Alemanha, Espanha e França. Mesmo com elevados índices de irradiação solar em todo seu território, o uso desta fonte não tem relevância expressiva como em outros países, nem o mesmo desenvolvimento de outras fontes renováveis como a eólica, com $6,7 \%$ em relação a capacidade geradora brasileira, ou a biomassa, com 9,4\%. As fontes solares hoje representam apenas 0,05\% da geração de energia no Brasil, segundo a Agência Nacional de Energia Elétrica (CONSULTORIA LEGISLATIVA, 2017).

Ainda segundo a ANEEL (2005), a energia solar pode ser utilizada diretamente para iluminação, aquecimento de água e ainda para geração de potência elétrica. A energia solar pode ainda ser convertida diretamente em energia elétrica por meio de efeitos da radiação, dentre os quais o termoelétrico e fotovoltaico.

Dentre os materiais mais adequados para a conversão da radiação solar em energia elétrica, os quais são usualmente chamados de células solares ou fotovoltaicas, destaca-se o silício, um ponto que pode ser positivo no investimento de energia fotovoltaica, já que no Brasil encontram-se grandes reservas de quartzo de qualidade, que podem gerar importante vantagem competitiva para a produção de silício com alto grau de pureza, células e módulos solares, produtos esses de alto valor agregado. Segundo SILVA (2015), cerca de $80 \%$ das células fotovoltaicas são fabricadas a partir do silício cristalino.

Segundo a Associação Brasileira de Energia Solar Fotovoltaica (ABSOLAR, 2016), a geração de energia elétrica por fonte solar proporciona benefícios socioeconômicos e ambientais.

A média anual de irradiação global apresenta uma boa uniformidade no Brasil, de acordo com Pereira et al. (2006), com médias relativamente altas em todo o território. Os valores de irradiação solar global incidente em qualquer região do território brasileiro (1500 - 2500 Wh. $\mathrm{m}^{-2}$ ) são superiores aos da maioria dos países europeus, como Alemanha (900 - $1250 \mathrm{Wh} / \mathrm{m}^{2}$ ) e França $\left(900-1650 \mathrm{Wh} / \mathrm{m}^{2}\right)$, onde projetos de aproveitamentos solares são amplamente difundidos.

A necessidade de aumento da oferta de energia se elevou no Brasil, como publicado pela Empresa de 
Pesquisa Energética (EPE, 2016). Houve um aumento de 158,9kWh/mês em 2012 para 159,8kWh/mês em 2016. Tal elevação se deu acompanhando o estímulo dado ao consumidor para aquisição de aparelhos elétricos o que, consequentemente, resultou em maior consumo de energia. É necessário destacar que o consumo médio de energia por consumidor possui relação com a renda da população e com PIB - Produto Interno Bruto. Se a população passa a ter maior poder aquisitivo, a tendência é que haja uma elevação do consumo de energia.

A WWF-Brasil (2015) apresenta dados relevantes sobre a energia fotovoltaica como a grande capacidade de geração de empregos associados à cadeia produtiva, a proximidade dos centros de demanda de energia, a capacidade de se somar com outras fontes renováveis e o reduzido impacto ambiental no seu processo produtivo.

Apesar das condições favoráveis brasileiras para tornar o país um grande produtor de energia elétrica a partir do uso intensivo de células fotovoltaicas, as iniciativas em curso são ainda bastante restritas. O Brasil em 1994 criou o PRODEEM (Programa de Desenvolvimento Energético de Estados e Municípios) para aquisição de sistemas fotovoltaicos para geração de energia elétrica para as comunidades isoladas, atendendo a 7.000 comunidades em todo o país. Este programa foi incorporado ao Programa Luz para Todos, criado em 2003 com o objetivo de atender as localidades remotas não eletrificadas no território nacional. Segundo dados da ANEEL (2015), desde 2004, já foram instalados 2.046 sistemas fotovoltaicos.

Já informações da WWF-Brasil (2015) mostram que a Agência Nacional de Energia Elétrica (ANEEL) promulgou algumas legislações para assegurar ao mercado as regras e normas para que a geração, aquisição e distribuições de energia fossem claras e objetivas a todos os interessados no processo. O Decreto no 5.163/2.004 determina que a aquisição de energia elétrica proveniente de empreendimentos de geração distribuída seja precedida de chamada pública, promovida diretamente pelo agente de distribuição, e a Resolução Normativa ANEEL 481/2012 permite que projetos fotovoltaicos de até $30 \mathrm{MW}$ tenham desconto de $80 \%$ nas Tarifas de Uso dos Sistemas de Transmissão e Distribuição (TUST e TUSD) ao longo dos 10 primeiros anos de operação, o que permite reduzir o preço final da energia. Só que os descontos valem apenas para projetos que entraram em operação até o final de 2017.

A Resolução ANEEL 482/2012, que estabelece as regras do net metering para a geração distribuída, determina que as concessionárias de distribuição passem a cobrar apenas o saldo líquido entre energia entregue ao consumidor descontada da energia gerada por ele e injetada na rede, além de definir outras condições, como medidores e requisitos de rede, para viabilizar essa troca. O termo "geração distribuída" é dado para sistemas de pequeno porte instalados em residências.

A WWF-Brasil (2015) aponta ainda a necessidade de uma política de governo para que haja o desenvolvimento do setor fotovoltaico no país, como a isenção fiscal e tributária, tais como PIS-COFINS, IPI, Imposto de Renda e CSLL (Contribuição Social sobre Lucro Líquido), ao setor fotovoltaico de produção de células e módulos fotovoltaicos e, inclusive, os diversos equipamentos envolvidos na produção desta fonte de energia, além da necessidade de incentivos financeiros para as empresas do setor e a criação de uma demanda mínima anual de $1.000 \mathrm{MW}$ de fontes de geração fotovoltaica em leilões de energia para garantir um desenvolvimento continuado no setor desta fonte energética.

Outro fator importante apontado é a necessidade de criação de linhas de financiamento para o consumidor para a aquisição dos sistemas, além de uma maior divulgação dos benefícios desta fonte de geração de energia renovável.

Um fator a ser observado é que a ANEEL não incluiu a fonte de energia fotovoltaica no Plano Nacional de Energia 2030, indicando o pouco peso estratégico desta fonte energética na política pública brasileira. Interessante notar que a pouca relevância dada a esta fonte de energia, ao levantar a opinião de consumidores e formadores de opinião das comunidades de negócios, revelou que esses são receptivos às energias limpas e otimistas de que a energia eólica e a solar serão as responsáveis por uma maior parte da matriz elétrica.

Assim, o presente artigo busca estudar se há benefícios em empreendimentos que possuem energia fotovoltaica em habitações de interesse social do programa do governo federal, Minha Casa, Minha Vida, em relação aos que não possuem este tipo de energia.

\section{MATERIAL E MÉTODOS}

A área de concentração deste trabalho foi a energia fotovoltaica e, para tanto, buscou-se literaturas existentes acerca do assunto abordado, com fim de analisar o mercado de energia, ações de sustentabilidade e comportamento de seus consumidores.

Foram realizadas simulações utilizando as informações do consumo médio de energia mensal de famílias brasileiras, pesquisas em empresas responsáveis pela 
implantação do sistema de energia fotovoltaica, construtoras e legislações sobre o tema no país, a fim de identificar a viabilidade e os atrativos comerciais e benéficos legais para o consumidor e construtoras

Também foi realizada uma pesquisa de opinião (Quadro 1) através de um questionário semiestruturado contendo oito perguntas fechadas, a fim de verificar o conhecimento da população em relação à energia fotovoltaica e ações de sustentabilidade em empreendimentos. As entrevistas foram realizadas durante o mês de outubro, novembro e dezembro de 2017, de forma on line e sem identificação para que a pesquisa não tivesse desvios e abrangesse o maior número de pessoas possível.

Quadro 1. Perguntas da pesquisa de opinião.

\begin{tabular}{|l|l|}
\hline $\mathbf{1}$ & Você sabe o que é energia fotovoltaica? \\
\hline $\mathbf{2}$ & $\begin{array}{l}\text { A energia fotovoltaica em um empreendimento } \\
\text { residencial/ casa seria um item possivelmente decisivo } \\
\text { em sua opinião final para compra? }\end{array}$ \\
\hline $\mathbf{4}$ & $\begin{array}{l}\text { Você pagaria a mais para ter um empreendimento } \\
\text { residencial/ casa com este benefício? }\end{array}$ \\
\hline $\begin{array}{l}\text { Você acredita ser importante os empreendimentos } \\
\text { residenciais/ casa serem entregues para seus clientes } \\
\text { com itens sustentáveis? Lâmpadas de LED, torneiras de } \\
\text { duplo acionamento, reaproveitamento de água da } \\
\text { chuva, torneira pressmatic, norma desempenho, } \\
\text { coletores recicláveis (resíduos recicláveis, pilha e } \\
\text { bateria, lâmpadas e óleo), conforto acústico e térmico, } \\
\text { por exemplo }\end{array}$ \\
\hline $\mathbf{5}$ & Você sabe o que são Mudanças Climáticas? \\
\hline $\mathbf{6}$ & $\begin{array}{l}\text { Você tem o conhecimento que a energia fotovoltaica } \\
\text { possui o benefício direto e indireto para a redução das } \\
\text { mudanças climáticas e impactos socioambientais? }\end{array}$ \\
\hline $\mathbf{7}$ & $\begin{array}{l}\text { "Você acompanha as legislações sobre energia } \\
\text { fotovoltaica no país? }\end{array}$ \\
\hline $\mathbf{8}$ & $\begin{array}{l}\text { Você sabia que o Brasil é um dos países que possui o } \\
\text { maior potencial de produção de energia solar no } \\
\text { planeta? }\end{array}$ \\
\hline
\end{tabular}

Trabalhando com dados levantados através de informações bibliográficas, pesquisas em sites e empresas, foi realizado alguns comparativos relacionados aos pontos positivos e negativos de se investir em energia fotovoltaica em um empreendimento Minha Casa, Minha Vida faixas 2 e 3.

\section{RESULTADOS E DISCUSSÃO}

\section{Cálculo estimado de Placas Fotovoltaicas por unidade residencial}

As informações a seguir foram obtidas através de pesquisas em empresas que realizam a instalação de painéis de energia fotovoltaica, construtoras e dados de consumo de energia fornecido pela Empresa de Pesquisa Energética (EPE), conforme informado o dado anteriormente. Ademais, as empresas pesquisadas solicitaram que seus nomes não fossem divulgados.

Segundo dados do EPE, a média de consumo de energia por residência no Brasil é aproximadamente 159 kWh/mês. Para esse consumo são necessárias 3 placas fotovoltaicas, ocupando uma área de cerca de $6,2 \mathrm{~m}^{2}$, segundo empresa especializada.

Com o preço médio de mercado de $\mathrm{R} \$ 2.500,00 /$ placa instalada e levando em consideração que para este consumo o valor médio da conta é de $\mathrm{R} \$ 123,00 /$ mês, o retorno do investimento seria em 5 anos, caso o consumidor o fizesse da forma particular.

\section{Sistema de crédito de energia com as concessionárias}

O sistema de energia fotovoltaica por geração distribuída multifamiliar, funciona da seguinte forma, a energia mensal gerada pelas placas fotovoltaicas é enviada para rede da concessionária local de energia, depois é revertido em créditos, contemplando o valor da energia gasta na unidade residencial.

Será cobrado pela concessionária o valor da taxa de iluminação pública. Caso a família ultrapasse no valor gerado naquele respectivo mês de geração de energia fotovoltaica, este será cobrado normalmente pela mesma a quantidade excedente de kwh/mês em sua conta de energia pela concessionária. Caso não seja consumido um valor maior que o mínimo permitido, o que sobrar deste consumo ficará reservado para o próximo mês, ou subsequente para o abatimento em sua conta de energia futura e deve-se pagar o valor mínimo mensal obrigatório para concessionária.

\section{Benefícios para as construtoras}

Os benefícios para a construtora estão desde a preferência do público por empreendimentos sustentáveis, que apresentam uma perspectiva de redução na conta de energia evidenciando o comprometimento da empresa com a sustentabilidade e inovação tecnológica até a possiblidade de atrair mais investidores e bancos financiadores. Há também a possibilidade de conseguir um projeto de Green Bonds com esta ação, tendo, assim, maior facilidade de empréstimos em bancos, conforme informado pelo site do BNDES. 
Segundo o site do BNDES a emissão de Green Bonds valoriza o apoio do banco a iniciativas de geração de energia renovável: entre 2003 e 2016, somente no setor de energia eólica, o BNDES aprovou 87 operações de crédito, num total de $\mathrm{R} \$ 28,5$ bilhões de crédito, proporcionando aumento de capacidade instalada de cerca de $10,7 \mathrm{GW}$.

\section{Investimento}

O investimento da construtora pode ser através de parceiros como Green Bonds, fundos de investimento em sustentabilidade, bancos investidores, projetos voltados para matriz energética limpa, renovável e com baixa emissão de Gases de Efeito Estufa.

0 investimento para instalação de células fotovoltaicas em um empreendimento de 450 unidade, gerando cerca de $635 \mathrm{MWh}$, tem um custo aproximado de 3 milhões de reais.

Como visto é necessário um alto investimento da construtora, que deve verificar a viabilidade da implantação deste projeto, uma vez que os bancos financiadores do programa Minha Casa, Minha Vida, possuem um teto máximo de valor de investimento por empreendimento e também há um teto máximo de valor pelo qual o imóvel pode ser vendido aos clientes que se encaixam nesta faixa.

Assim, caso o custo de implantação exceda os limites do programa, este deve ser arcado apenas pela construtora que poderá, de forma indireta ter o retorno deste investimento.

\section{Dificuldades}

Uma das maiores dificuldades encontradas na implantação de sistemas de energia fotovoltaica em empreendimentos multifamiliares são algumas concessionárias que ainda terão que realizar a implantação destes novos modelos de distribuição de energia, pois o mercado ainda está iniciando este novo processo e as concessionárias estão acostumadas com padrão já implantado de placas fotovoltaicas para residências unifamiliares. Com este novo modelo multifamiliar de distribuição, as concessionárias ainda estudam padrões verificando as realidades de cada município.

Outro ponto que dificulta a implantação do sistema é a demanda de área, cada placa tem cerca de $2 \mathrm{~m}^{2}$, ou seja, para empreendimentos multifamiliares a área demandada pode ser alta, o que deve ser compatibilizada com o projeto arquitetônico.

\section{Benefícios para os clientes}

Alguns municípios possuem isenção de parte do IPTU, através das legislações de IPTU Verde, alguns destes voltados para ações sustentáveis incluindo a geração de energia fotovoltaica, ou seja, o morador deste empreendimento pode conseguir desconto em seu IPTU por haver geração de energia fotovoltaica em seu condomínio, um exemplo é na cidade de Palmas/TO onde o desconto do IPTU Verde incluiu em seus itens a geração de energia fotovoltaica.

Outro ponto importante é a redução das emissões dos Gases de Efeito Estufa emitidos pela geração de energia através de hidrelétricas e termoelétricas, que são as maiores fontes de geração de energia hoje no país, também há redução de impactos socioambientais que as tipologias citadas trazem, como alagamento de grandes áreas, impacto direto sobre comunidades e municípios das áreas que foram alagadas, possíveis problemas voltados para perdas de fauna e flora.

As fábricas de painéis fotovoltaicos possuem sistema de logística reversa dos painéis, desta forma o descarte das placas é feito de forma responsável e sustentável. Quanto a durabilidade do sistema, a garantia dos fornecedores quanto a geração de energia é de 25 anos, garantindo o retorno do investimento e geração de economia por um longo período.

\section{Resultado da pesquisa de opinião}

De acordo com os dados coletados nas entrevistas, realizou-se a compilação dos dados para apresentar seus resultados (Figura 1 ).

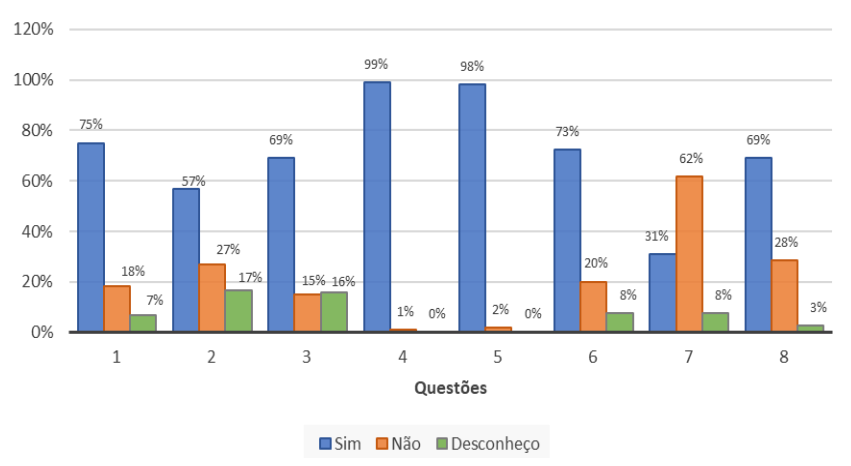

Figura 1. Índice de respostas do questionário.

Pode-se verificar que grande parte dos entrevistados possuem conhecimento do que é energia fotovoltaica. Dos entrevistados, $57 \%$ daria preferência para imóveis 
que possuem este tipo de energia renovável e 69\% estariam dispostos a pagar a mais para obter um imóvel com este tipo de geração de energia.

Nota-se que quase todos os entrevistados acreditam ser importante as ações sustentáveis nos imóveis e tem conhecimento do que são as Mudanças Climáticas o que sugere conhecimento do impacto das ações sustentáveis neste contexto.

Foi verificado também na pergunta 7 , que os entrevistados não acompanham as legislações sobre energia fotovoltaica.

\section{CONCLUSÃO}

Pode-se verificar durante o estudo que as concessionárias ainda não estão completamente preparadas para absorver a energia fotovoltaica gerada pelos empreendimentos. Observou-se também o investimento que deve ser feito pelas construtoras que muitas vezes pode não ser financiado pelos bancos devido aos limites do Minha Casa, Minha Vida, além da demanda de área para implantação no sistema.

Viu-se também que o retorno para as construtoras é, em grande parte, indireto através de maior visibilidade de mercado, atração de investidores e de clientes com perfil mais voltado para as questões sustentáveis, que se dispõem, inclusive a pagar por empreendimentos com valor mais alto, mas que possuem alternativas sustentáveis. Como pode-se ver na pesquisa realizada este público existe e está cada vez mais atento às questões climáticas. Além disso, as construtoras podem se beneficiar com a redução do IPTU através da legislação do IPTU Verde, presente em várias cidades.

Segundo o resultado da pesquisa realizada pode-se verificar também o entendimento da população quanto às mudanças climáticas e a importância das iniciativas que beneficiam o meio ambiente, um estimulo ainda maior às construtoras que poderão ter um produto mais atrativo com estas premissas.

Da mesma forma, os compradores poderão se beneficiar do sistema com o desconto de IPTU, além da redução da conta de energia, maior facilidade de financiamento bancário e maior valorização do imóvel.

Assim, pode-se concluir que a implantação do sistema de energia fotovoltaica é viável para os empreendimentos Minha Casa, Minha Vida, Faixas 2 e 3, como um investimento para as construtoras e para os compradores com retorno financeiro a médio e longo prazo.

Outro ponto crucial de decisão são os vários benefícios de sustentabilidade e inovação que a construtora pode obter em relação ao mercado, investidores, fundos de pensão e possíveis empréstimos voltados para sustentabilidade assim como Green Bonds.

Deve-se observar também o amadurecimento das concessionárias em relação aos empreendimentos multifamiliares com a geração de energia fotovoltaica e também o posicionamento do governo em relação a esse tipo de energia no país, podendo trazer novos investimentos e legislação, fazendo com que haja um incentivo ainda maior a disseminação da mesma.

\section{REFERÊNCIAS}

ANEEL - Agência Nacional de Energia Elétrica. Atlas da energia elétrica do Brasil. 2.ed. Brasília, 2005.

ANEEL - Agência Nacional de Energia Elétrica. Resolução Normativa n. 435/2011. Brasília, 2011.

ANEEL - Agência Nacional de Energia Elétrica. Dados geração distribuída no Brasil. 2015. Disponível em: http://www2.aneel.gov.br/scg/rcgMicro.asp

ABSOLAR - Associação Brasileira de Energia Solar Fotovoltaica. Geração distribuída solar fotovoltaica. Rio de Janeiro: Encontro Nacional dos Agentes do Setor Elétrico, 2016.

CONSULTORIA LEGISLATIVA - CÂMARA DOS DEPUTADOS. Energia solar no Brasil: situação e perspectivas. Estudo Técnico, 2017

EPE - Empresa de Pesquisa Energética. O compromisso do Brasil no combate às mudanças climáticas: produção e uso da energia. Rio de Janeiro, 2016.

ECHEGARAY, F. Understanding stakeholders' views and support for solar energy in Brazil. Journal of Cleaner Production, p.1-9, 2013.

MMA - Ministério do Meio Ambiente. Construção sustentável. 2018. Disponível em: http://www.mma.gov.br/cidadessustentaveis/urbanismo-sustentavel/constru\%C3\%A7\%C3\%A3osustent\%C3\%A1vel

NREL - National Renewable Energy Laboratory. Swera (Beta release). 2015. Disponível em: https://maps.nrel.gov/swera

PEREIRA, E.B. et al. Atlas brasileiro de energia solar. São José dos Campos: INPE, 2006.

SILVA, R.M. Energia solar: dos incentivos aos desafios. Brasília: Texto para discussão no 166, 2015.

WWF - BRASIL. Desafios e oportunidades para a energia solar fotovoltaica no Brasil: recomendações para políticas públicas. Brasília, 2015. 